\title{
Is there any association between Hashimoto's thyroiditis and thyroid cancer? A retrospective data analysis*
}

\author{
Existe associação entre tireoidite de Hashimoto e câncer de tireoide? Análise retrospectiva \\ de dados
}

\section{Daysi Maria de Alcântara-Jones ${ }^{1}$, Tania Freitas de Alcântara-Nunes ${ }^{2}$, Bruno de Oliveira Rocha ${ }^{3}$, Rafael Daltro de Oliveira $^{3}$, Allan Chastinet Pitangueira Santana ${ }^{3}$, Fernanda Tavares de Alcântara ${ }^{3}$, Thais Magalhães de Faria ${ }^{4}$, Igor Campos da Silva ${ }^{5}$, Leila Maria Batista Araújo ${ }^{6}$}

Alcântara-Jones DM, Alcântara-Nunes TF, Rocha BO, Oliveira RD, Santana ACP, Alcântara FT, Faria TM, Silva IC, Araújo LMB. Is there any association between Hashimoto's thyroiditis and thyroid cancer? A retrospective data analysis. Radiol Bras. 2015 Mai/Jun;48(3):148-153.

Abstract Objective: To evaluate the association between Hashimoto's thyroiditis (HT) and papillary thyroid carcinoma (PTC).

Materials and Methods: The patients were evaluated by ultrasonography-guided fine needle aspiration cytology. Typical cytopathological aspects and/or classical histopathological findings were taken into consideration in the diagnosis of HT, and only histopathological results were considered in the diagnosis of PTC.

Results: Among 1,049 patients with multi- or uninodular goiter (903 women and 146 men), 173 (16.5\%) had cytopathological features of thyroiditis. Thirty-three (67.4\%) out of the 49 operated patients had PTC, 9 (27.3\%) of them with histopathological features of HT. Five (31.3\%) out of the 16 patients with non-malignant disease also had HT. In the groups with HT, PTC, and PCT+HT, the female prevalence rate was $100 \%, 91.6 \%$, and $77.8 \%$, respectively. Mean age was $41.5,43.3$, and 48.5 years, respectively. No association was observed between the two diseases in the present study where HT occurred in $31.1 \%$ of the benign cases and in $27.3 \%$ of malignant cases $(p=0.8)$.

Conclusion: In spite of the absence of association between HT and PCT, the possibility of malignancy in HT should always be considered because of the coexistence of the two diseases already reported in the literature.

Keywords: Thyroid nodule; Cytopathology; Thyroid neoplasms; Thyroiditis; Ultrasonography.

Resumo Objetivo: Avaliar a associação entre tireoidite de Hashimoto (TH) e carcinoma papilífero da tireoide (CPT).

Materiais e Métodos: Pacientes foram avaliados por punção aspirativa guiada pela ultrassonografia. Para TH consideraram-se aspectos característicos da citopatologia e/ou achados histopatológicos clássicos. O diagnóstico de CPT foi considerado apenas pela histopatologia.

Resultados: De 1.049 pacientes portadores de bócios uni-multinodulares (903 femininos e 146 masculinos), 173 (16,5\%) tinham quadro citopatológico de tireoidite. Dos 49 pacientes operados, $33(67,4 \%)$ revelaram CPT, dos quais 9 (27,3\%) tinham a glândula com quadro histopatológico de TH. Dos 16 pacientes sem malignidade, 5 (31,3\%) exibiam também TH. Nos grupos TH, CPT e CPT+TH, a proporção de acometimento do gênero feminino foi, respectivamente, 100\%, 91,6\% e 77,8\%. A distribuição da média da idade (anos) nos três grupos foi 41,5, 43,3 e 48,5. Não houve associação entre as duas doenças, neste estudo, em que a TH esteve presente em $31,3 \%$ dos casos benignos e em $27,3 \%$ dos casos malignos ( $p=0,8$ ).

Conclusão: Não houve associação entre TH e CPT, mas a possibilidade de malignidade em TH deve ser sempre lembrada em razão da concomitância das duas doenças, já revelada na literatura.

Unitermos: Nódulo da glândula tireoide; Citopatologia; Neoplasias da glândula tireoide; Tireoidite; Ultrassonografia.

* Study developed at Hospital São Rafael, Salvador, BA, Brazil.

1. Associate Professor III, Department of Pathology and Legal Medicine at Universidade Federal da Bahia (UFBA), Endocrinologist at Hospital São Rafael, Salvador BA, Brazil.

2. Graduate Student of Medicine, Universidade Salvador (Unifacs), Salvador, BA, Brazil.

3. Graduate Students of Medicine, School of Medicine, Universidade Federal da Bahia (UFBA), Salvador, BA, Brazil.

4. Graduate Student, Escola Bahiana de Medicina e Saúde Pública (EBMSP), Salvador, BA, Brazil.

5. Physician Assistant, Pathologist, Hospital São Rafael, Salvador, BA, Brazil.

6. Associate Professor IV, Universidade Federal da Bahia, Salvador, BA, Brazil.

Mailing Address: Dra. Daysi Maria Alcântara Jones. Rua Professor Sabino Silva, 1077, ap. 402, Jardim Apipema. Salvador, BA, Brazil, 40155-250. E-mail: daysijones @gmail.com.

\section{INTRODUCTION}

Hypothyroidism affects $0.7 \%$ to $5.7 \%$ of the general population $^{(1)}$ and the main cause for such a condition in the population of iodine-sufficient areas is chronic lymphocytic thyroiditis - Hashimoto's thyroiditis (HT). On the other hand, papillary thyroid carcinoma (PTC) is the most frequent disease among malignant endocrinopathies whose incidence is increasing also among children and young adults ${ }^{(2)}$ and whose diagnosis is usually made as nodules are detected in the thyroid gland (TN).

Received October 16, 2014. Accepted after revision November 10, 2014. 
Thyroid nodular disease is extremely frequent, reaching as much as $50 \%$ of the population above the age of $60^{(3)}$, and ultrasonography-guided fine needle aspiration cytology (US-guided FNAC) is the most sensitive and specific technique for the diagnosis of malignant nodules and to select those patients who should be referred to surgery ${ }^{(4,5)}$.

The inflammatory process associated with HT causes important structural distortion of the thyroid, so that images frequently demonstrate nodular masses raising doubts whether such masses are true nodules (which might be malignant) or not (the so called pseudonodules). Such glandular structure distortion may lead to a less demanding approach in the evaluation of TN, postponing the evaluation by USguided FNAC.

Recently, a greater frequency of PTC has been observed among patients with $\mathrm{HT}^{(6-8)}$, a fact that has been denied by other authors ${ }^{(9,10)}$. Thus, it is indispensable to know whether there is an association between both diseases. Once such an association is confirmed, the presence of a TN in a patient with HT should be considered as a risk factor for development of a neoplasm, which should indicate a deeper investigation to rule out the presence of malignancy in such cases.

The present study was aimed at evaluating whether there is an association between malignancy and HT.

\section{MATERIALS AND METHODS}

In the period between January and December of 2011, 1,049 consecutive patients (903 female and 146 male patients) with either uninodular or multinodular goiter underwent US-guided FNAC, comprising a total of 1,521 evaluated TNs. Data from all patients were retrospectively obtained from the files of the pathological anatomy service. The collection and subsequent analysis of patients' data was duly approved by the Committee for Ethic in Research of the institution under No. 55/2011.

US scans were performed by different specialists at the service, utilizing a SSD 1700 model Aloka apparatus, with color Doppler, with a 7.5 MHz transducer, and each nodule was measured in its largest dimension. All punctures were performed by a single observer, as described by Kim et al. ${ }^{(11)}$.

Nodules smaller than $1 \mathrm{~cm}$ were aspirated once or twice, while nodules between 1 and $3 \mathrm{~cm}$ were aspirated twice or three times, in radial direction. Nodules $>3 \mathrm{~cm}$ in their largest dimension were evaluated at their upper, middle and lower thirds, also in radial direction, and when heterogeneous suggesting to be confluent, the punctures were aimed at areas with different echogenicity patterns. In cases of more than one nodule within the same lobe, the largest nodules, or those with echogenic characteristics suggesting malignancy were initially punctured ${ }^{(12,13)}$. Specimens of nodules in the right lobe were identified at the plates as LD; those from the left lobe, as LE; and from the isthmus, as (I), besides patient's identification.

The cytopathological analyses were performed by several observers, all of them specialists of the cytopathology service, who randomly analyzed a given number of specimens on their routine duties. Whenever there were doubts as regards the cytopathological diagnosis, the material was analyzed by a different cytopathologist of the service, and a consensus was sought. Materials considered to be satisfactory were those which presented, in at least two plates, six or more groups of well-preserved follicular cells, each group comprising at least ten cells ${ }^{(14)}$. Some of the cytopathologists were less demanding, considering that a large amount of colloid in a small-sized TN could be classified as Bethesda II or "colloid nodule". Not every cytopathologist mentioned the Bethesda classification.

Among the 49 patients who underwent surgery, it was possible to make 93 comparisons between the cytopathological diagnosis and histopathology, per studied lobe. In those cases of uninodular goiter, the material study corresponded to the nodule. In the cases of two or more nodules in a given thyroid lobe, the cytopathological diagnosis corresponded to the pool of material collected from those several nodules.

The diagnostic value of US-guided FNAC in this material was studied by means of the likelihood ratio, as that is the best method to evaluate such type of diagnostic test (USguided FNAC). In such a method the results classification comprises six categories, three of them undetermined, representing an important limiting factor in this diagnostic method.

The data were evaluated by means of the statistical software SPSS (Statistical Package for the Social Sciences) release 20.0, for the calculation of the mean and proportions of the studied population. The Fisher's exact test evaluated the correlation between the variables "thyroiditis" and "thyroid cancer". The statistical significance was defined as being $p<0.05$.

\section{RESULTS}

Among the 1,049 patients submitted to US-guided FNAC, $903(86.1 \%)$ were women with a mean age of 49.97 \pm 14.7 years (minimum values: 7 years; maximum value: 88 years). Forty-nine (M/F : 8/41) out of all patients were operated and their mean age was $45.6 \pm 16.1$ years. In the HT, PTC and PTC+HT groups (histopathological results), the rates of involvement among women were, respectively, 100\%, $91.6 \%$ and $77.8 \%$. The mean age distribution in the three groups was $41.5,43.3$ and 48.5 years, respectively.

No complications were observed in the studied patients, and no preparation was required for the intervention, not even anticoagulant therapy interruption. One of the patients presented with thrombocytopenia $(72,000)$ at the time of the procedure and neither intra- nor extraglandular bleeding was observed.

Table 1 shows cytopathological and histopathological diagnoses regarding 93 thyroid lobes of 49 patients submitted to US-guided FNAC and surgery. In $7.8 \%$ of the FNACs performed in the 1,049 patients the collected material was 
Table 1-Cytopathological diagnoses (US-guided FNAC) of 93 analyzed specimens (49 patients submitted to surgery).

\begin{tabular}{lcc}
\hline Cytopathological diagnoses & $n$ & Percentage \\
\hline Unsatisfactory material (Bethesda I) & 2 & $2.1 \%$ \\
Negative for malignancy (Bethesda II) & 37 & $39 \%$ \\
Suspected malignancy (Bethesda III-V) & 44 & $47 \%$ \\
Positive for malignancy (Bethesda VI) & 10 & $10.7 \%$ \\
Total & 93 lobes \\
\hline Histopathological diagnoses & & \\
\hline Adenomatous goiter & 43 & $46.2 \%$ \\
Follicular adenoma & 2 & $2.1 \%$ \\
Hashimoto's thyroiditis & 3 & $3.2 \%$ \\
Benign Hürthle cells tumor & 3 & $3.2 \%$ \\
Papilliferous carcinoma & 40 & $43 \%$ \\
Medullary carcinoma & 2 & $2.1 \%$ \\
Total & 93 & $100 \%$ \\
\hline
\end{tabular}

insufficient for diagnosis, although amongst the patients submitted to surgery, that percentage was $2.1 \%$. Thirty-nine patients were referred for surgery due to diagnosis or suspicion of malignancy at cytopuncture (confirmed in 33 patients $-84.6 \%$ ), while ten patients were referred for surgery due to the size of their thyroid nodules, and among those patients there were no cases of unsatisfactory material for diagnosis. The two cases of unsatisfactory material for diagnosis $(2.1 \%)$ corresponded to patients with multinodular goiter, with cytopathological diagnosis Bethesda IV and V in one of the lobes, and insufficient material for diagnosis in the contralateral lobe. In the general evaluation of the 93 cytopathological correlations, 2 cases $(2.1 \%)$ resulted in unsatisfactory material for diagnosis.

Table 2 shows the distribution of the 1,521 nodules according to their location in the gland. One observes that $57.4 \%$ of the examined patients had uninodular goiter. Among the 96 patients with cytopathological diagnosis or suspicion of malignancy, $75(78.1 \%)$ had uninodular goiter. Of the patients in this group who were submitted to surgery, $63.3 \%$ presented with uninodular goiter. However, among the patients who were submitted to surgery because of increased volume of the gland, $90 \%$ had multinodular goiter.

The Bethesda classification was utilized in $70.9 \%$ of the cytopathological analyses performed (Table 3 ). The likelihood ratio was high for diagnosis of malignancy when the level V was diagnosed and especially for level VI, where no false-positive result was observed. Among the patients operated because of suspected malignancy, US-guided FNAC allowed for selection of $84.6 \%$ of malignant nodules. The present study proved the high specificity (94.7\%), sensitivity $(83 \%)$, positive predictive value $(100 \%)$ and negative predictive value $(94.6 \%)$ in the 93 cytopathological correlations.

Amongst the 1,049 patients presenting with nodular goiter, $173(16.4 \%)$ presented with cytopathological signs of thyroiditis. Among the 49 patients submitted to surgery, 5 (10.2) were histopathologically diagnosed with HT, 33
Table 2-Number of lobes studied at US-guided FNAC.

\begin{tabular}{llcc}
\hline \multirow{2}{*}{ Goiter } & Lobe & $\begin{array}{c}\text { Number of } \\
\text { patients }\end{array}$ & $\begin{array}{c}\text { Number of } \\
\text { nodules }\end{array}$ \\
\hline \multirow{2}{*}{ Uninodular } & Right lobe & 325 & 325 \\
& Left lobe & 265 & 265 \\
& Isthmus & 12 & 12 \\
Multinodular & Right lobe and left lobe & 390 & 780 \\
& Right lobe and isthmus & 18 & 36 \\
& Left lobe and isthmus & 14 & 28 \\
& Right lobe, left lobe and isthmus & 25 & 75 \\
\multirow{2}{*}{ Total } & & 1,049 & 1,521 \\
\hline
\end{tabular}

Table 3-Malignancy percentage in thyroid nodules pre-operatively evaluated by FNAC, utilizing the Bethesda classification.

\begin{tabular}{lccc}
\hline $\begin{array}{l}\text { Cytopathological } \\
\text { diagnoses }\end{array}$ & $\begin{array}{c}\text { Malignancy/number } \\
\text { of nodules }\end{array}$ & $\begin{array}{c}\text { Percentage } \\
\text { of malignancy }\end{array}$ & $\begin{array}{c}\text { Likelyhood } \\
\text { ratio }\end{array}$ \\
\hline Bethesda I & $0 / 1$ & $0 \%$ & - \\
Bethesda II & $2 / 21$ & $9.5 \%$ & 0.7 \\
Bethesda III & $4 / 8$ & $50 \%$ & 0.85 \\
Bethesda IV & $9 / 14$ & $64.2 \%$ & 1.5 \\
Bethesda V & $11 / 12$ & $91.6 \%$ & 10 \\
Bethesda VI & $10 / 10$ & $100 \%$ & $>277$ \\
\hline
\end{tabular}

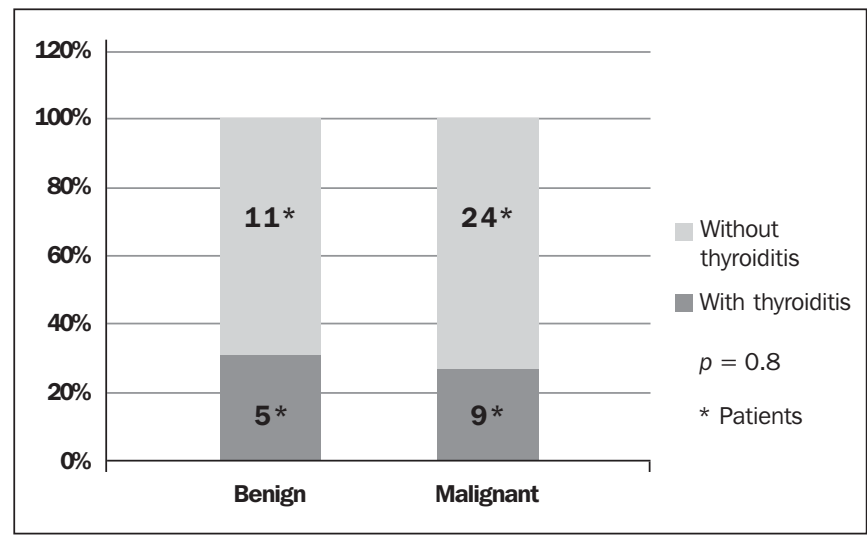

Figure 1. Coexistence of Hashimoto thyroiditis in patients with diagnosis of benignity and malignancy in thyroid nodules (papilliferous thyroid carcinoma).

(67.3\%) presented PTC, $9(27.3 \%)$ of them with concomitant histopathological diagnosis of HT. Two patients $(4.2 \%)$ had medullary carcinoma whose cytopathological diagnoses were confirmed at histopathology. Among the ten patients submitted to surgery due to increased nodular volume, 5 (31.3\%) also presented with HT and one PTC case was histopathologically diagnosed (one case of false-negative result). In the present study, no association was observed between PTC and HT. Hashimoto thyroiditis was present in $31.1 \%$ of the benign cases and in $27.3 \%$ of the malignant cases (Fisher's exact test, $p=0.8$ ) (Figure 1).

\section{DISCUSSION}

The controversy on the association between HT and PTC persists in the literature. Dailey et al. ${ }^{(6)}$ were the first au- 
thors to report such an association, finding PTC in $17.7 \%$ of their 278 patients with HT, corresponding to a higher incidence of malignancy than that observed in the general population, a result that has been confirmed by other authors $^{(8,15,16)}$. However, no statistical significance was observed in other studies ${ }^{(9,10,17)}$.

Jankovic et al. ${ }^{(8)}$ undertook a systematic review on original studies investigating the association between HT and PTC, and divided he articles into two categories, namely, those which sought the association among cytopathological diagnoses (FNAC), and those which sought the association among histopathological diagnoses. The rate of prevalence of such association was $1.2 \%$ in eight studies (FNAC) of 18,023 analyses, and $27.56 \%$ in eight studies of 9,884 surgical specimens (HP). Association was observed only in the latter group (RR ranging between 0.3 and 1.0 in the FNAP group and RR ranging between 1.15 and 4.16 , in the HP group).

Morphological, immunohistochemical and molecular characteristics are common to both diseases, a fact that reinforces such a supposition. The inflammatory process that is always present in HT is common to other conditions considered as predisposing to neoplasms, a fact that has been attributed to the production of free radicals, and to accumulation of oxidative DNA damage and possible facilitator of neoplasia development. Figure 2 shows the histopathological pattern of PTC with lymphocytic infiltration, fibrosis and glandular atrophy, similar to what occurs at HT, a fact that is attributed by other authors to the attempt of the body to limit the pathological process ${ }^{(18)}$.

RET rearrangement in papillary thyroid cancer is an oncogene activation marker for thyroid follicular cells, particularly for PTC; however it presents low specificity as it has been found in other tumors and also in HT. Rhoden et al. ${ }^{(19)}$ have reported that $68 \%$ of their HT samples were positive for such marker. Additionally, RET/PTC 1 was found in PTC specimens at levels similar to those found in HT

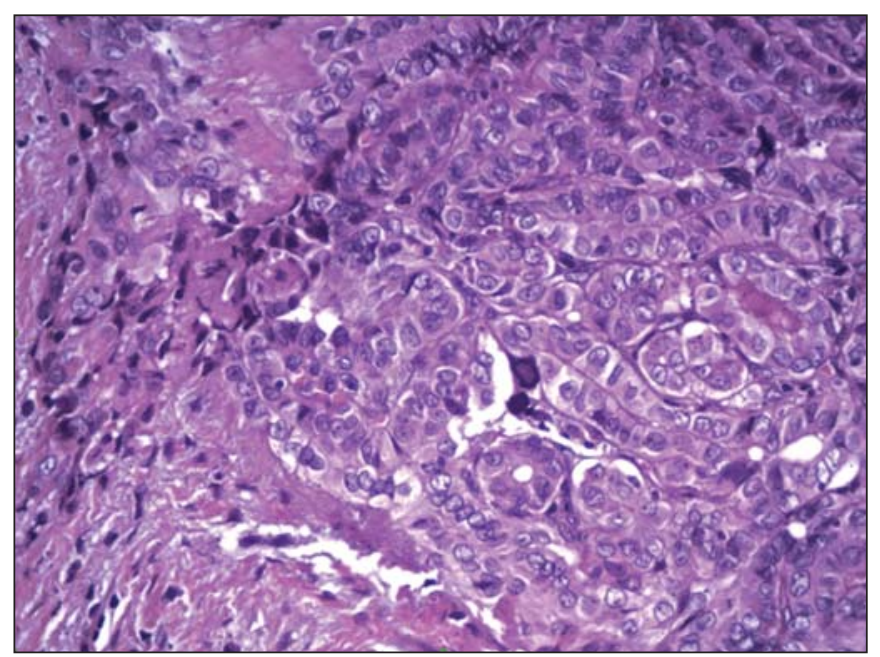

Figure 2. Circumscribed neoplastic papilliferous thyroid carcinoma. Presence of inflammatory cells, especially lymphocytes (lymphocytic thyroiditis). samples, corroborating a possible association between these diseases.

By resorting to immunohistochemistry, one observed increased expression of PI3K/Akt pathway (phosphatidylinositol-3-kinase protein/specific cellular signaling cascade of the kinase protein of serine/threonine) in thyroid with PTC and HT as compared with normal tissue, suggesting a probable mechanism linking the inflammatory reaction to the thyroid carcinogenesis. According to Larson et al., patients presenting increased expression of this pathway face three times higher chance of developing PTC, corroborating a strong relation between inflammatory reaction and development of cancer ${ }^{(18)}$.

Royer et al. ${ }^{(20)}$, by means of PCR, have identified the hOGG1 gene (encoding human 8-oxoguanine DNA glycosylase), producer of a DNA-repairing enzyme whose loss of heterozygosity occurs in $94 \%$ of patients with PTC, in $73 \%$ of patients with HT, and in $8 \%$ of patients with benign lesion. According to the authors, that fact reinforces the accumulated damaging action on the DNA and leads to the assumption that aberrant genetic changes accumulate for a long time in the thyroid follicular epithelium, possibly as a precursor of PTC.

Despite the current controversy as regards the association between both diseases, it seems to be clear that the coexistence of the two entities lead to a better prognosis in relation for those patients presenting with PTC and HT than for those PTC without HT. Such a fact is demonstrated by a smaller number of additional surgeries after the initial surgical treatment, lower accumulated radiotherapy dose, and persistence of the disease, as previously mentioned ${ }^{(8,21)}$.

Predominance of female patients was observed in the three groups - HT, PTC and PTC+HT - a fact that has already been widely reported in the literature, particularly in relation to autoimmunity. One seeks to explain such a phenomenon by means of hormone fluctuations and pregnancy. As regards pregnancy, one assumes that the accumulation of fetal cells in the maternal thyroid might be involved in the unleashing of the autoimmune process.

The present study confirmed that FNAC is one of the most accurate methods to investigate the thyroid nodules malignancy, due to its high sensitivity and specificity, a fact that is confirmed by several authors ${ }^{(5,22-24)}$. The calculation of the likelihood ratio demonstrates that the Bethesda levels $\mathrm{V}$ and VI are strongly suggestive of malignancy, reinforcing data in the literature where no false-positive result is reported for ultrasonography-guided FNAC ${ }^{(23-25)}$. On the other hand, false-negative cases have been reported in the literature and, like in the present study, were associated with the presence of a large-volume thyroid nodule possibly related to difficulty in sampling at US-guided FNAC.

Evaluations classified as levels V and VI practically affirm malignancy, a fact that is in accordance with several studies where the rate of false positive results at such levels, especially at level VI, is extremely low ${ }^{(22,23)}$. 
As the different levels of FNAC diagnoses are evaluated by likelihood ratio, one realizes that a Bethesda II diagnosis rules out malignancy with great accuracy. On the other hand, there is a paradox in Bethesda categories III and IV, justified by the small number of cases, considering that, while the plain frequency revealed that more than $50 \%$ of such cytologies were from malignant nodules, the likelihood ratio points towards ruling out malignancy. In the literature, the Bethesda level III corresponds to 5\%-15\% of malignancy, while Broome et al. ${ }^{(25)}$ found $20 \%$ of malignant cases. The authors of the present study believe that cytopathologists' adaptation to the new classification may have caused such a high malignancy percentage at such Bethesda level.

The Bethesda classification created in $2009^{(22)}$ was not utilized by all cytopathologists, but it has clearly separated benign cases (level II) from the malignant ones (level VI), leaving a percentage of undetermined diagnoses (levels III, IV and V) whose likelihood ratio between each other is not clearly defined.

Most patients evaluated by ultrasonography-guided FNAC and those who underwent surgery for suspected malignancy had uninodular goiter, however, almost all patients with benign nodules at ultrasonography-guided FNAC who underwent surgery for increased volume of the nodule represented cases of multinodular goiter, which might suggest that the indication for surgery in cases of large goiter (benign) may have been influenced by the multiplicity of nodules. The questioning on whether the presence of single nodules increases the suspicion for malignancy persists in the literature ${ }^{(12,13)}$.

With a greater percentage of malignant nodules being selected, one might question whether such a selection might be a consequence of the improvement in the ultrasonography-guided FNAC technique or an actual increase in the incidence of malignant thyroid nodules, a possibility that is advocated by some authors ${ }^{(2)}$.

It is estimated that about $5 \%$ out of all thyroid nodules in a population are malignant, a percentage which in the presently studied population would correspond to 52 patients with cancer. In the present study, the authors found that 34 out of the 49 patients submitted to surgery had cancer ( 42 malignant nodules). Considering that the active search for such patients was finished closely to the cytological diagnosis, there is a possibility that more cases of malignancy would be surgically diagnosed, a fact that may represent a selection bias in the present study.

Another limitation in the present study was the fact that different observers evaluated the cytopathologies, in spite of the fact that all cytopathologists were committed to reevaluate the cases of undetermined material.

Surprisingly, the present study did not find any case of follicular carcinoma, previously indicated as comprising $20 \%$ of the malignant thyroid nodules ${ }^{(4,5)}$. A similar study was developed by Coorough et al. ${ }^{(26)}$ evaluating 3,981 cases and found neither follicular carcinomas nor oxyphilic follicular cell tumors (Hürthle) (either benign or malignant). The absence of follicular carcinoma, that is a more aggressive tumor as compared with papilliferous carcinomas, has drawn the attention of authors from different parts of the world. There is the hypothesis that the iodine supplementation status in the population may be the determining factor of such a change in the prevalence of thyroid follicular carcinoma.

In the present study, the finding of two medullary carcinomas is highlight, corresponding to $4.2 \%$ of all patients submitted to surgery in the studied population, a rate that is similar to the one reported by other series ${ }^{(27)}$. Assuming that $5 \%$ of the general population presents with thyroid nodules, and that among such individuals $4.2 \%$ present with thyroid medullary carcinoma, in 1,049 individuals (as in the present study) one would expect to find 2 cases $(4.2 \%)$ of medullary carcinoma among the 49 patients submitted to surgery. That leads to the conclusion that US-guided FNAC diagnosed all the expected medullary carcinoma cases in the 1,049 studied patients. Thus, it was demonstrated that ultrasonography-guided FNAC is a good method for the diagnosis of such pathology, although some authors do not agree with such an assertion. ${ }^{(27)}$.

Based on the evidences reported by several studies regarding the association between both diseases, the authors of the present study assume that due to the small number of patients submitted to surgery in the present study population, it was not possible to prove such an association. Such evidences corroborate the necessity of regularly evaluating not only the thyroid function but also patients presenting with HT by means of US. Therefore, further studies with a greater number of patients will be necessary to evaluate the association between both entities.

\section{CONCLUSION}

There was no association between HT and PTC, a fact possibly related to the size of the study sample, but the possibility of malignancy in HT should be kept in mind because of the concomitant occurrence of both diseases already reported in the literature.

\section{REFERENCES}

1. Garmendia Madariaga A, Santos Palacios S, Guillén-Grima F, et al. The incidence and prevalence of thyroid dysfunction in Europe: a meta-analysis. J Clin Endocrinol Metab. 2014;99:923-31.

2. Vergamini LB, Frazier AL, Abrantes FL, et al. Increase in the incidence of differentiated thyroid carcinoma in children, adolescents, and young adults: a population-based study. J Pediatr. 2014;164: $1481-5$.

3. Mazzaferri EL. Management of a solitary thyroid nodule. N Engl J Med. 1993;328:553-9.

4. Alcântara DMF. Valor diagnóstico da biópsia da tireóide. Estudo comparativo. [Dissertação de mestrado]. Salvador, BA: Universidade Federal da Bahia; 1985.

5. Alcântara-Jones DM, Lavinas-Jones JM, Daltro R, et al. Valor diagnóstico da punção aspirativa da tireoide (PAAF): estudo comparativo da técnica com e sem uso da ultrassonografia [resumo]. In: XV Latin American Thyroid Congress; 2013 Mar 20-23; Florianópolis, SC. 
6. Dailey ME, Lindsay S, Skahen R. Relation of thyroid neoplasms to Hashimoto disease of the thyroid gland. Arch Surg. 1955;70:291-7.

7. Loh KC, Greenspan FS, Dong F, et al. Influence of lymphocytic thyroiditis on the prognostic outcome of patients with papillary thyroid carcinoma. J Clin Endocrinol Metab. 1999;84:458-63.

8. Jankovic B, Le KT, Hershman JM. Clinical review: Hashimoto's thyroiditis and papillary thyroid carcinoma: is there a correlation? J Clin Endocrinol Metab. 2013;98:474-82.

9. Maceri DR, Sullivan MJ, McClatchney KD. Autoimmune thyroiditis: pathophysiology and relationship to thyroid cancer. Laryngoscope. 1986;96:82-6.

10. Anil C, Goksel S, Gursoy A. Hashimoto's thyroiditis is not associated with increased risk of thyroid cancer in patients with thyroid nodules: a single-center prospective study. Thyroid. 2010;20:601-6.

11. Kim MJ, Kim EK, Park SI, et al. US-guided fine-needle aspiration of thyroid nodules: indications, techniques, results. Radiographics. 2008;28:1869-89.

12. American Thyroid Association (ATA) Guidelines Taskforce on Thyroid Nodules and Differentiated Thyroid cancer, Cooper DS, Doherty GM, et al. Revised American Thyroid Association Management Guidelines for patients with thyroid nodules and differentiated thyroid cancer. Thyroid. 2009;19:1167-214.

13. Frates MC, Benson CB, Charboneau JW, et al. Management of thyroid nodules detected at US: Society of Radiologists in Ultrasound consensus conference statement. Radiology. 2005;237:794800 .

14. Kini SR, Smith-Purslow MJ. Adequacy, reporting system, and cytopreparatory technique. In: Kini SR, editor. Guide to clinical aspiration biopsy: thyroid. 2nd ed. New York-Tokyo: Igaku-Shoin; 1996. p. 13-28.

15. Okayasu I, Fujiwara M, Hara Y, et al. Association of chronic lymphocytic thyroiditis and thyroid papillary carcinoma. A study of surgical cases among Japanese, and white and African Americans. Cancer. 1995;76:2312-8.

16. Campos LA, Picado SM , Guimarães AV , et al. Thyroid pappilary carcinoma associated to Hashimoto's thyroiditis. Braz J Otorhinolaryngol. 2012;78:77-80.

17. Mazokopakis EE, Tzortzinis AA, Dalieraki-Ott EI, et al. Coexistence of Hashimoto's thyroiditis with papillary thyroid carcinoma. A retrospective study. Hormones. 2010;9:312-7.

18. Larson SD, Jackson LN, Riall TS, et al. Incresed incidence of welldifferentiated thyroid cancer associated with Hashimoto thyroiditis and the role of the PI3k/Akt pathway. J Am Coll Surg. 2007 204:764-75.

19. Rhoden KJ, Unger K, Salvatore G , et al. RET/papillary thyroid cancer rearrangement in nonneoplastic thyrocytes: follicular cells of Hashimoto's thyroiditis share low-level recombination events with a subset of papillary carcinoma. J Clin Endocrinol Metab. 2006; 91:2414-23.

20. Royer MC, Zhang H, Fan CY, et al. Genetic alterations in papillary thyroid carcinoma and Hashimoto thyroiditis: an analysis of hOGG 1 loss of heterozygosity. Arch Otolaryngol Head Neck Surg. 2010; 136:240-2.

21. Dvorkin S, Robenshtok E, Hirsch D, et al. Differentiated thyroid cancer is associated with less aggressive disease and better outcome in patients with coexisting Hashimoto thyroiditis. J Clin Endocrinol Metab. 2013;98:2409-14.

22. Theoharis CG, Schofield KM, Hammers L, et al. The Bethesda thyroid fine-needle aspiration classification system: year 1 at an academic institution. Thyroid. 2009;19:1215-23.

23. Nou E, Kwong N, Alexander LK, et al. Determination of the optimal time interval for repeat evaluation after a benign thyroid nodule aspiration. J Clin Endocrinol Metab. 2014;99:510-6.

24. Yoon JH, Kwak JY, Moon HJ, et al. The diagnostic accuracy of ultrasound-guided fine-needle aspiration biopsy and the sonographic differences between benign and malignant thyroid nodules $3 \mathrm{~cm}$ or larger. Thyroid. 2011;21:993-1000.

25. Broome JT, Solorzano CC. The impact of atypia/follicular lesion of undetermined significance on the rate of malignancy in thyroid fine-needle aspiration: evaluation of the Bethesda System for Reporting Thyroid Cytopathology. Surgery. 2011;150:1234-41.

26. Coorough N, Hudak K, Buehler D, et al. Fine needle aspiration of the thyroid: a contemporary experience of 3981 cases. J Surg Res 2011;170:48-51.

27. American Thyroid Association Guidelines Task Force, Kloos RT, Eng C, et al. Medullary thyroid cancer: management guidelines of the American Thyroid Association. Thyroid. 2009;19:565-612. 